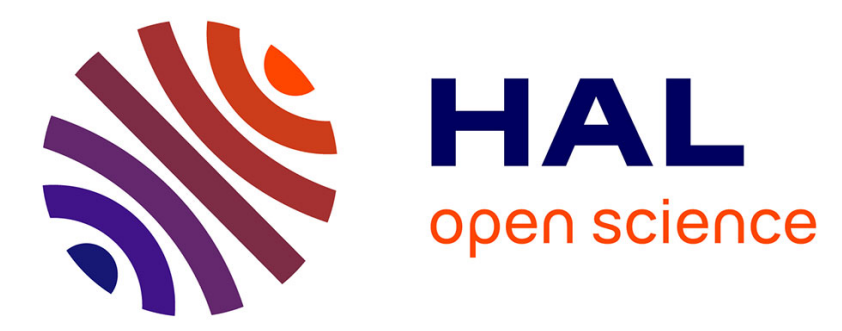

\title{
Principal Component Analysis Method-Based Research on Agricultural Science and Technology Website Evaluation
}

\author{
Jian Ma
}

\section{- To cite this version:}

Jian Ma. Principal Component Analysis Method-Based Research on Agricultural Science and Technology Website Evaluation. 9th International Conference on Computer and Computing Technologies in Agriculture (CCTA), Sep 2015, Beijing, China. pp.369-381, 10.1007/978-3-319-48354-2_37 . hal01614220

\author{
HAL Id: hal-01614220 \\ https://hal.inria.fr/hal-01614220
}

Submitted on 10 Oct 2017

HAL is a multi-disciplinary open access archive for the deposit and dissemination of scientific research documents, whether they are published or not. The documents may come from teaching and research institutions in France or abroad, or from public or private research centers.
L'archive ouverte pluridisciplinaire HAL, est destinée au dépôt et à la diffusion de documents scientifiques de niveau recherche, publiés ou non, émanant des établissements d'enseignement et de recherche français ou étrangers, des laboratoires publics ou privés.

\section{(c)(1)}

Distributed under a Creative Commons Attribution| 4.0 International License 


\title{
Principal Component Analysis Method-Based Research On
}

\section{Agricultural Science And Technology Website Evaluation}

\author{
Jian $\mathrm{Ma}^{1, \mathrm{a}, *}$ \\ ${ }^{1}$ Agricultural Information Institute of Chinese Academy of Agricultural Sciences, Beijing, $100081 ;{ }^{2}$ Key \\ Laboratory of Agricultural Information Service Technology (2006-2010), Ministry of Agriculture, The People's \\ Republic of China, Beijing, 100081 \\ a majian@caas.cn
}

\begin{abstract}
Agricultural science and technology website is a very important supporter of driving agricultural information and servicing agriculture. An evaluation method is proposed on agricultural science and technology website based on objective data and artificial ratings, using principal component analysis method. Finally the author used the model to evaluate 18 agricultural science and technology websites, and proposed some suggestions on development of agricultural science and technology websites based on the evaluation result which would act as reference to agricultural science and technology website construction.
\end{abstract}

Keywords: agricultural science and technology website,principal component analysis method,website evaluation

Agricultural science and technology website is an important window of agricultural science and technology departments and relevant units on the Internet to show their own image, also a concentrated expression of service ability and service level and service features, At the same time,also as a important carrier of serviceing "three rural" and promoting agricultural informationization. From the current point of view, although the agricultural science and technology website is rich in resources, but the quality is uneven, how to better improve the website construction is a problem urgent need to solve. A Scientific evaluation method, can make the website administrator to complete understanding of the operation of the site, consummate the existing problems, improve the quality of the website. On the basis of the research of the peer, the principal component analysis method is used,exploring a new method of comprehensive evaluating websites .

\section{1 overview of website evaluation method}

At present, there are no unified standards and methods for the evaluation of the website. The author consulted a large number of literature data, summarized the following two kinds methods of the evaluation of the website :

Foundation item: Intelligent search technology and method research of website platform 
(1) web link analysis

At present, Link analysis and web impact factor measure related to it are widely used to evaluate the websites. Link analysis through the number of sites are linked to reflect the quality of the site. The evaluation is on the basis that a web site is linked another website is approval and use of this website , and the content of two website is related; the more number of external links of a web site, Explain Its influence is greater. The network impact factor measure is based on the link analysis, reflect the influence of the web site by the size of web impact factor.

Although this method is applied to a wide range of applications, but it also has shortcomings: it only start from the link analysis of the website, not comprehensive evaluation of a website, the authority is to be verified. At the same time, the data used to analysis mostly get from Alta Vista or Google and other search engines, which makes the results depends too much on the search engine, but due to the drawbacks of itself, search engine may not included all external links and internal links of a website.

(2) analytic hierarchy process

Analytic hierarchy process divide the decision problem according to total target, sub target, evaluation criteria until the specific input sequential scheme is decomposed into different levels of the hierarchy and layer by layer analysis, ultimately,get the importance weights that the lowest level factor for the highest level factor.

Analytic hierarchy process can be used to evaluate the site, but the relative importance of each factor in the same level must be evaluated in the construction of evaluation matrix. This will have error inevitably due to the subjective behavior.

Based on the above research, In this paper, we give the evaluation index and calculation method of agricultural science and technology website, and use the principal component analysis method to analyze the evaluation index. Finally, the model is used to obtain the comprehensive ranking of 18 agricultural science and technology websites, and the relevant suggestions are given according to the evaluation results.

\section{2 principal component analysis method for the comprehensive evaluation of the principles and methods}

Principal component analysis is also called the principal weight analysis, which is an important method to study how to transform the multi index problem into a less comprehensive index. Because there is a certain degree of correlation between multiple variables, people naturally want to extract information from these indicators as quickly as possible through linear combination. Principal component analysis can change the problem of high dimensional space into a low dimensional space to deal with, make the problem become more simple, intuitive, and the comprehensive index of these less interaction and provide most of the information of the original index.

In practical application, the specific steps of principal component analysis are: 
(1) standardization of raw data

(2) set up the correlation coefficient matrix of variable

(3) obtain the eigenvalues and eigenvectors of the correlation matrix.

(4) the number of principal components is determined by the cumulative variance contribution rate, and the principal components are extracted.

(5) weighted synthesis of principal components, get comprehensive evaluation

\section{3 evaluation index and method of agricultural science and technology website}

The evaluation of agricultural science and technology website mainly investigation from the content of the website, website design and user operation three major aspects. Each of the major aspects of the index selection consider of agricultural science and technology website features. The evaluation model is shown in Figure 1:

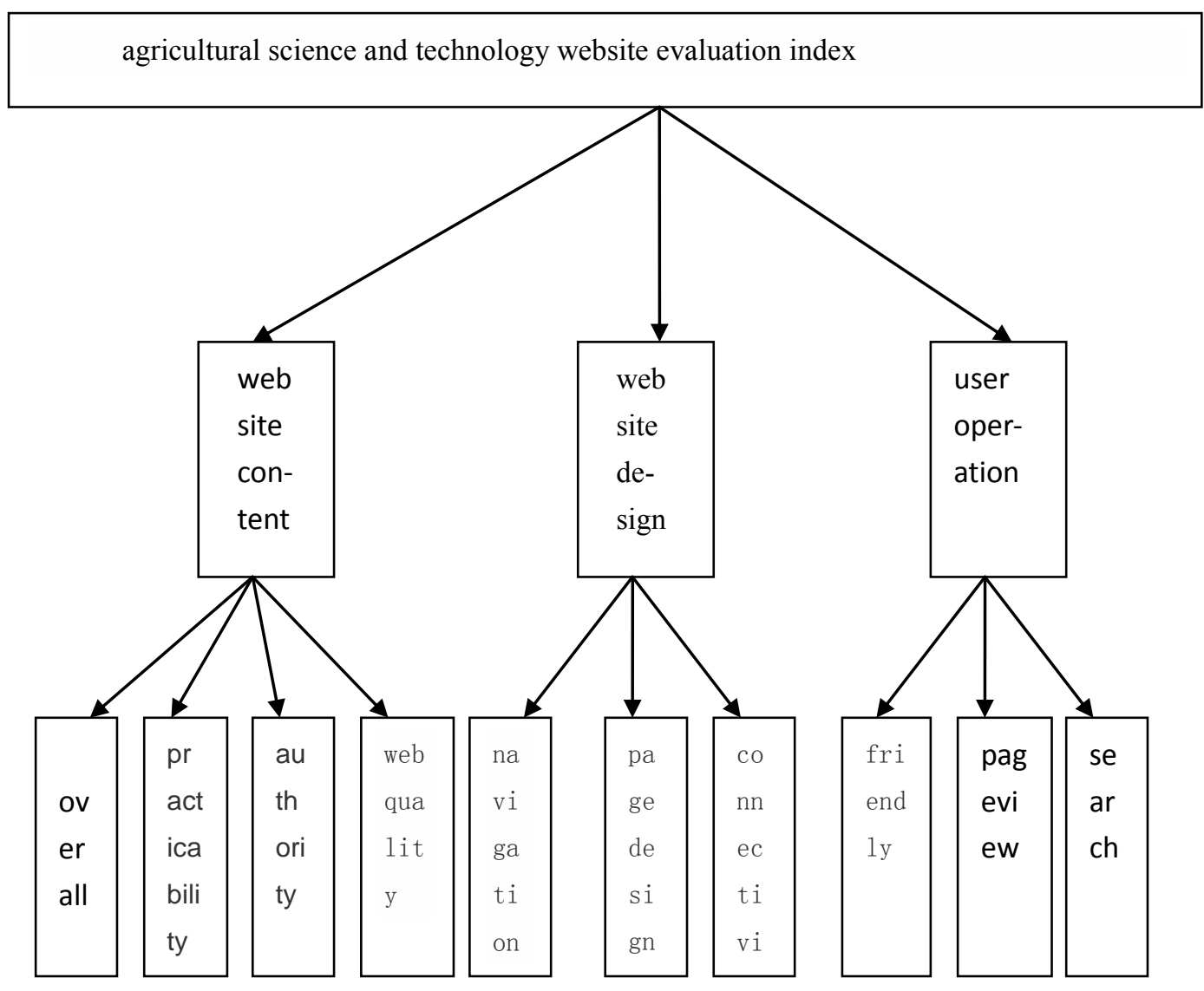

Figure 1 evaluation index model of agricultural science and technology website 
The evaluation method of the index is too dependent on the subjective score, so the evaluation of the importance of the indicators in the evaluation of the importance of a strong subjectivity. At the same time, simply rely on the objective data can not be a comprehensive reflection of agricultural science and technology website. So we make full use of the advantages of existing systems and professional personnel, the index can be described with the objective data as an objective data, can only rely on artificial score index scoring more than re synthesis method is implemented. The index data is more scientific. Specific practices are as follows:

(1) website content

Web content is good or bad is a valuable key of a agricultural science and technology website. For the content of the site we were from the following four aspects to Investigate:

Comprehensiveness. Comprehensiveness is the breadth of agricultural science and technology website contains content. Web site can be used to quantitatively expressed by the number of web pages. The number of sites webpages can be estimated approximately using the search engine included page numbers.

Practical application. Whether the choice of the content of the site is in line with the "three rural" needs, whether it is suitable for the specific user base, which is suitable for the "three rural" information. This indicator cannot be described by objective data, and it is determined by expert scoring method.

Authority. Authority is the impact of agricultural science and technology sites and the extent of the popularity of the site. This index can be described by using the website of agricultural science and technology anti link number, which the number of links from other sites to this site. The more the number of a website's anti link, the greater the influence, the greater the authority.

The quality of Webpage. Web quality evaluation can be from the user point of view. Bounce Bounce RateBounce RateBounce RaterBounce Rateate is an important index to measure the quality of web pages. The Bounce rate is the percentage of the total number of visits from a particular portal to visit a site, which only access to one page on the number of visits to the total number of visits. When the site's bounce rate is high, the quality of the page is very poor, do not attract users.

(2) website design

Good website design should have reasonable structure, the page is simple and beautiful, easy to use. For the website design we investigate from the following three aspects:

Navigation function. Navigation function for the user to use the entire site is essential. Design good navigation function can make the user more convenient, more quick browse information. This indicator is determined by expert scoring method. 
Page design. Mainly to examine the page of friendship, include that, the structure is clear, the layout is reasonable, Logo is beautiful, etc.. This indicator is determined by expert scoring method.

Connectivity. Effective connectivity mainly investigate the link to the page, if the webpage have broken link or dead link. This indicator can be used to described with broken link rate, broken link rate is the number of all the broken links of the website divided by the number of all links of the website.

(3) user operation

User operation is to measure the website good or bad from the users. For the user operation we investigate from the following three aspects:

(1) Friendly degree. Here is not to examine the degree of friendship from web design, but examine the entire web server response time, and page download time. Obviously, the response time of the server and the web page download times shorter, the higher the site the user-friendliness. Therefore, there are two indicators measure friendliness: server response time, page download time.

(2) User visits. User visits Is the number of user visits the site. we can use the average daily IP traffic number to describe user visits, visitors every page view can be described by Daily average page views.

(3) search function. search function for users to find resources is very important, well-designed site should have a comprehensive in-station search function, which should have advanced search and fuzzy queries. The index score is determined by experts. Detailed indicators and evaluation of the site's content as shown in Table 1:

Table 1 Evaluation System of agricultural science and technology website

$\begin{array}{lll}\text { Level indicators } & \begin{array}{l}\text { Secondary } \\ \text { indicators }\end{array} & \text { Evaluation Content }\end{array}$

website content Comprehensiveness. Include the number of pages

Practical application Experts rate, standard: meet the needs of agricultural information

Authority Number of anti-link

The quality of Bounce rate

Webpage

website design Navigation function Experts rate, standard: ease of navigation 


\begin{tabular}{lll}
\hline & Page design & Experts rate, standard:page friendly degree \\
Connectivity & Broken link rate \\
user operation & Friendly degree & Speed (download time, response time) \\
& User visits & average daily IP traffic, average daily Page view \\
& search function & Experts rate, standard: the station search function \\
\hline
\end{tabular}

\section{4 examples of application and analysis}

\section{1 evaluation object}

The evaluation object of this paper is 18 agricultural science and technology information website, which has 7 national agricultural science and technology website, 11 provincial agricultural science and technology website, as shown in table 2:

Table $2 \quad 18$ evaluation objects

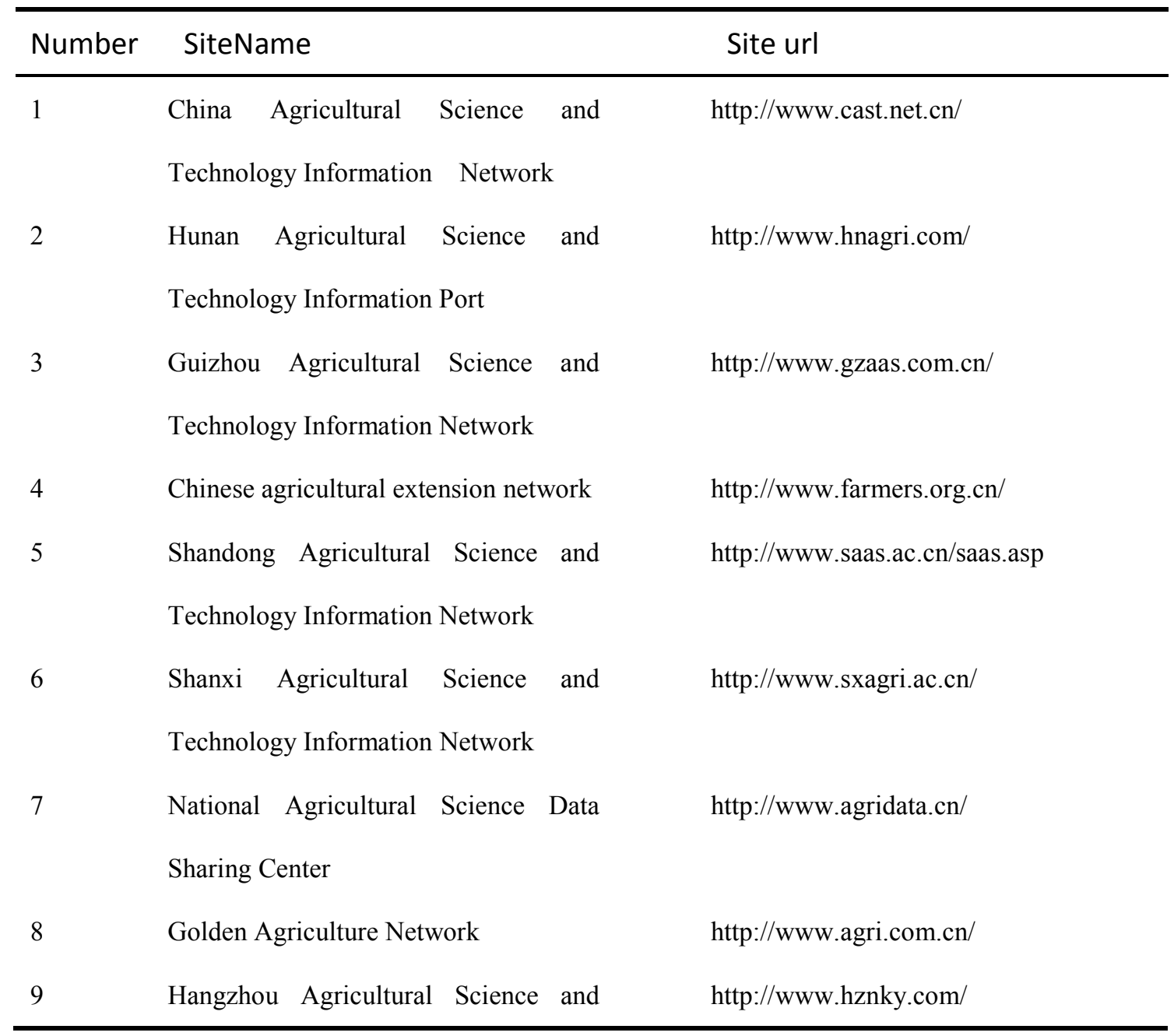




\begin{tabular}{|c|c|c|}
\hline & Technology Information Network & \\
\hline 10 & $\begin{array}{l}\text { Liaoning Luyuan Agricultural Science } \\
\text { and Technology Information Network }\end{array}$ & http://www.last.gov.cn/ \\
\hline 11 & Chinese Academy of Agricultural & http://www.caas.cn/ \\
\hline & Sciences Network & \\
\hline 12 & $\begin{array}{l}\text { Anhui Academy of Agricultural } \\
\text { Sciences Network }\end{array}$ & http://www.ahas.org.cn/ \\
\hline 13 & $\begin{array}{l}\text { Zhongshan, Guangdong Agricultural } \\
\text { Science and Technology Park }\end{array}$ & http://www.zsnk.com/ \\
\hline 14 & $\begin{array}{l}\text { Hainan Agricultural Science and } \\
\text { Technology } 110 \text { network }\end{array}$ & http://www.hnnj110.com/ \\
\hline 15 & Nong Bo Technology & http://www.aweb.com.cn/ \\
\hline 16 & $\begin{array}{l}\text { Beijing agricultural information } \\
\text { network }\end{array}$ & http://www.agri.ac.cn/ \\
\hline 17 & $\begin{array}{l}\text { Tianjin Agricultural Information } \\
\text { Network }\end{array}$ & http://www.tjagri.gov.cn/ \\
\hline 18 & Nine hundred million Network & http://www.new9e.com/ \\
\hline
\end{tabular}

\section{2 data sources}

Data sources of this paper are the following four:

(1) network technology resource monitoring, analysis, evaluation system.

The system long-term monitoring 18 agricultural science and technology website in Table 2, the system provided data included the number of pages, the number of anti-link, download time and the response time four indicators.

(2) artificial: This paper invited 5 of the author's colleagues, 5 ordinary users to form a group of experts. 5 of the author's colleagues engage in agricultural science and Technology Information Research for many years, while the other 5 are ordinary users that often used agricultural science and technology website.

Respectively, usability, navigation, page layout and search functions independently scoring four indicators, score interval $[0,1], 1$ on behalf of full marks, 0 on behalf of 0 . For each item of data to remove one of the highest and lowest scores, then averaging the remaining data is the index score. 
(3) Alexa:Alexa is a site that specialized publishing website ranking. Alexa every day collect more than $1000 \mathrm{~GB}$ of the information, not only give billions of web site links, but also rank for each of the sites. It can be said, Alexa is currently has the largest number of URL, released ranking information the most detailed site.

Alexa provides the data for: average daily IP access, the average daily amount of page view browsing and bounce rate

(4) Chinaz (Chinese webmaster station): is a specializes in providing information for Chinese site, technology, resources and services of the website, website existing millions of users.

Chinaz provides data for the number of broken links of the site and the total number of links to the site.

\section{3 data extraction}

Extracting data from the four data sources mentioned in 4.2, after finishing get the relevant index data of 18 agricultural science and technology site as shown in Table 3:

Table 3 index data of 18 agricultural science and technology website

\begin{tabular}{lllllllllllll}
\hline nu & Inc & Prac & Anti & Boun & Navi & Page & Bro & Down & Res & Dai & daily & Sear \\
mb & Lude & Tica & link & Ce & Gati & Desi & Ken & Load & Pon & ly & page & Ch \\
er & Page & Bili & & rate & On & gn & Link & time & Se & IP & view & Func \\
& Num & ty & & & Func & & rate & (s) & time & Acc & bro & tion \\
& ber & & & & tion & & & & (s) & ess & wse & \\
\hline 1 & 937 & 0.85 & 2540 & $33.30 \%$ & 0.9 & 0.92 & 0.146 & 1.18 & 0.02 & 360 & 2160 & 0.83 \\
2 & 2140 & 0.73 & 1470 & $81 \%$ & 0.7 & 0.51 & 0.026 & 0.619 & 0.44 & 780 & 1170 & 0.82 \\
3 & 2520 & 0.9 & 1420 & $78 \%$ & 0.88 & 0.9 & 0.102 & 0.494 & 0.27 & 300 & 300 & 0.65 \\
4 & 20700 & 0.73 & 2480 & $60 \%$ & 0.9 & 0.85 & 0.037 & 0.445 & 0.22 & 300 & 300 & 0.87 \\
5 & 4990 & 0.8 & 2680 & $37.50 \%$ & 0.85 & 0.8 & 0.4 & 0.864 & 0.01 & 780 & 4680 & 0.76 \\
6 & 2470 & 0.85 & 1830 & $77.80 \%$ & 0.78 & 0.85 & 0.048 & 4.909 & 0.23 & 420 & 420 & 0.25 \\
7 & 1060 & 0.87 & 1190 & $12.50 \%$ & 0.79 & 0.74 & 0.021 & 0.623 & 0.06 & 1500 & 180000 & 0.98 \\
8 & 16400 & 0.92 & 723000 & $50.90 \%$ & 0.81 & 0.92 & 0.09 & 1.034 & 0.04 & 9600 & 37440 & 0.84 \\
9 & 1040 & 0.78 & 349 & $50 \%$ & 0.85 & 0.74 & 0.225 & 0.784 & 2.77 & 180 & 230 & 0.83 \\
10 & 4360 & 0.72 & 691 & $50 \%$ & 0.86 & 0.8 & 0.032 & 6.599 & 0.07 & 250 & 270 & 0.2 \\
11 & 6800 & 0.88 & 20100 & $34.10 \%$ & 0.97 & 0.9 & 0.076 & 0.541 & 0.01 & 6000 & 23400 & 0.8 \\
12 & 477 & 0.72 & 353 & $67 \%$ & 0.85 & 0.85 & 0.017 & 0.848 & 2.87 & 240 & 280 & 0.7 \\
13 & 116 & 0.68 & 47 & $84 \%$ & 0.6 & 0.64 & 0.07 & 1.338 & 3.89 & 180 & 200 & 0.82 \\
14 & 728 & 0.54 & 503 & $60 \%$ & 0.78 & 0.82 & 0.164 & 3.611 & 0.1 & 120 & 120 & 0.75 \\
15 & 7580 & 0.71 & 79500 & $35.30 \%$ & 0.85 & 0.9 & 0.1 & 2.127 & 0.04 & 64200 & 46680 & 0.8 \\
16 & 7080 & 0.68 & 18500 & $57.90 \%$ & 0.88 & 0.83 & 0.04 & 2.539 & 0.05 & 660 & 990 & 0.75 \\
17 & 873 & 0.57 & 2360 & $54 \%$ & 0.95 & 0.8 & 0.069 & 12.244 & 0.08 & 160 & 220 & 0.85 \\
\hline
\end{tabular}




\begin{tabular}{lllllllllllll}
\hline 18 & 2760 & 0.95 & 1560 & $18 \%$ & 0.8 & 0.75 & 0.09 & 0.829 & 0.17 & 180 & 210 & 0.8 \\
\hline
\end{tabular}

Note: the number column is one one corresponding to the number in Table 2.

\section{4 comprehensive ranking of agricultural science and technology website based on principal component analysis}

In this paper, using SPSS13.0 execute the principal component analysis, and the specific steps are:

(1) standardization of raw data

In principle component analysis method, the standard method is Normal standardization, and for the practical application, according to the difference of the index, divided the bigger the better and the smaller the better. So we take the following standard method:

With $m$ evaluation object, $n$ evaluation index. All data constitute a $m * n$ order matrix $X=(X 1, X 2, \ldots$ $\mathrm{Xn})$. Where $\mathrm{Xi}$ is a $\mathrm{m}^{*} 1$ dimensional vector. Let $\max (\mathrm{Xi})$ is the maximum value of $\mathrm{Xi}$, $\min (\mathrm{Xi})$ is the minimum value of $\mathrm{Xi} . \operatorname{Max}(\mathrm{Xi})=(\max (\mathrm{Xi}), \max (\mathrm{Xi}), \ldots \operatorname{Max}(\mathrm{Xi})) \mathrm{T}$ is a $\mathrm{m}^{* 1}$ dimension vector, Min $(\mathrm{Xi})=(\min (\mathrm{Xi}), \min (\mathrm{Xi}), \ldots \mathrm{Min}(\mathrm{Xi})) \mathrm{T}$ is the $\mathrm{m}^{*} 1$ dimension vector, For the bigger the better type index, the formula is:

$$
\mathrm{X}_{\mathrm{i}}^{*}=\frac{\mathrm{X}_{\mathrm{i}}-\operatorname{Min}\left(\mathrm{X}_{\mathrm{i}}\right)}{\max \left(X_{i}\right)-\min \left(X_{i}\right)}
$$

For the smaller the better type index, the formula is:

$$
\mathrm{X}_{\mathrm{i}}^{*}=\frac{\operatorname{Max}\left(\mathrm{X}_{\mathrm{i}}\right)-\mathrm{X}_{\mathrm{i}}}{\max \left(X_{i}\right)-\min \left(X_{i}\right)}
$$

In this paper, $n=12, m=18$. The bigger the better type included web number, practical, the number of anti link, navigation, page design, average daily IP access, the average daily amount of page view browsing and search functions eight indexs. The smaller the better type included bounce rate, broken link rate, download time and response time four.

\section{(2) Use SPSS 13.0 for factor analysis}

Get the standardized data input SPSS data editing window,the 12 indicators were named X1 X12. Select Analyze->Data Reduction->Factor menu item in the SPSS windows, Tune out factor analysis main interface and move the variable X1 X12 into the variables box, click the OK button, execute factor analysis process. Get the characteristic roots and variance contribution rate table shown in Figure 4 and factor loading matrix as shown in Table 5: 
Table 4 characteristic root and variance contribution rate table

Total Variance Explained

\begin{tabular}{|l|r|r|r|r|r|r|}
\hline \multirow{2}{*}{ Component } & \multicolumn{3}{|c|}{ Initial Eigenvalues } & \multicolumn{3}{|c|}{ Extraction Sums of Squared Loadings } \\
\cline { 2 - 7 } & \multicolumn{1}{|c|}{ Total } & \% of Variance & Cumulative $\%$ & \multicolumn{1}{c|}{ Total } & \% of Variance & Cumulative $\%$ \\
\hline 1 & 3.008 & 25.069 & 25.069 & 3.008 & 25.069 & 25.069 \\
2 & 2.076 & 17.300 & 42.370 & 2.076 & 17.300 & 42.370 \\
3 & 1.525 & 12.710 & 55.080 & 1.525 & 12.710 & 55.080 \\
4 & 1.287 & 10.726 & 65.806 & 1.287 & 10.726 & 65.806 \\
5 & 1.125 & 9.371 & 75.177 & 1.125 & 9.371 & 75.177 \\
6 & .836 & 6.966 & 82.143 & & & \\
7 & .725 & 6.042 & 88.185 & & & \\
8 & .586 & 4.882 & 93.067 & & & \\
9 & .306 & 2.549 & 95.616 & & & \\
10 & .272 & 2.268 & 97.883 & & & \\
11 & .159 & 1.326 & 99.210 & & & \\
12 & .095 & .790 & 100.000 & & & \\
\hline
\end{tabular}

Extraction Method: Principal Component Analysis.

In Table 4 in total column is each factor corresponding characteristic root, In this case extract five common factors; \%of Variance column is the variance contribution of each factor; Cumulative \% column is the cumulative variance contribution rate of each factor, As can be seen, the first five factors can explain $75.177 \%$ of the variance.

Table 5 factor load matrix

Component Matrix ${ }^{a}$

\begin{tabular}{|l|r|r|r|r|r|}
\hline & \multicolumn{5}{|c|}{ Component } \\
\cline { 2 - 6 } & 1 & 2 & 3 & \multicolumn{1}{|c|}{4} & \multicolumn{1}{|c|}{5} \\
\hline$\times 1$ & .582 & -.074 & .604 & .083 & -.175 \\
$\times 2$ & .526 & .383 & .146 & -.363 & .564 \\
$\times 3$ & .484 & .140 & .637 & .130 & -.079 \\
$\times 4$ & .690 & .202 & -.581 & .001 & .047 \\
$\times 5$ & .587 & -.585 & -.250 & -.185 & -.044 \\
$\times 6$ & .684 & -.471 & .128 & -.174 & -.037 \\
$\times 7$ & -.119 & -.054 & .262 & .704 & .451 \\
$\times 8$ & .223 & .735 & .237 & -.376 & .019 \\
$\times 9$ & .634 & -.380 & -.173 & .129 & .204 \\
$\times 10$ & .400 & .011 & .024 & .411 & -.471 \\
$\times 11$ & .424 & .511 & -.349 & .489 & .227 \\
$\times 12$ & .252 & .592 & -.197 & .078 & -.495 \\
\hline
\end{tabular}

Extraction Method: Principal Component Analysis.

a. 5 components extracted.

(3) using factor analysis result execute principal component analysis

Get Table 5's data input SPSS Data Editor window, Column named a1 a5. Then click on the menu item Transform-> Compute, Recall Compute variable dialog, Enter zl = al / SQRT (3.008) in the 
dialog box, Click the OK button, you can get a first feature vector. Similarly, it can be calculated for all the feature vectors, which results are shown in Table 6:

Table 6 feature vector matrix

\begin{tabular}{llllll}
\hline \multicolumn{1}{rr}{$\mathrm{z} 1$} & \multicolumn{1}{r}{$\mathrm{z} 2$} & \multicolumn{1}{c}{$\mathrm{z} 3$} & \multicolumn{1}{c}{$\mathrm{z} 4$} \\
\hline $\mathrm{x} 1$ & 0.336 & -0.051 & 0.489 & 0.073 & -0.165 \\
$\mathrm{x} 2$ & 0.303 & 0.266 & 0.118 & -0.32 & 0.532 \\
x3 & 0.279 & 0.097 & 0.516 & 0.115 & -0.074 \\
x4 & 0.398 & 0.14 & -0.47 & 0.001 & 0.044 \\
x5 & 0.338 & -0.406 & -0.202 & -0.163 & -0.041 \\
x6 & 0.394 & -0.327 & 0.104 & -0.153 & -0.035 \\
x7 & -0.069 & -0.037 & 0.212 & 0.621 & 0.425 \\
x8 & 0.129 & 0.51 & 0.192 & -0.331 & 0.018 \\
x9 & 0.366 & -0.264 & -0.14 & 0.114 & 0.192 \\
x10 & 0.231 & 0.008 & 0.019 & 0.362 & -0.444 \\
x11 & 0.244 & 0.355 & -0.283 & 0.431 & 0.214 \\
x12 & 0.145 & 0.411 & -0.16 & 0.069 & -0.467 \\
\hline
\end{tabular}

By multiplying the matrix of the original data with the eigenvector matrix, can obtained the 5 principal components Y1-Y5. Then the 5 main components weighted comprehensive, you can get the comprehensive score of the agricultural science and technology website, Specific data shown in Table 7.

The formula for calculating the comprehensive score is

$$
\mathrm{Y}=\frac{\lambda_{1}}{\sum_{\mathrm{i}=1}^{5} \lambda_{\mathrm{i}}} Y_{1}+\frac{\lambda_{2}}{\sum_{\mathrm{i}=1}^{5} \lambda_{\mathrm{i}}} Y_{2}+\mathrm{L}+\frac{\lambda_{5}}{\sum_{\mathrm{i}=1}^{5} \lambda_{\mathrm{i}}} Y_{5}
$$

$\mathrm{Y}$ is a composite score, $Y_{i}$ is the main component $\mathrm{i}, \lambda_{i}$ is the characteristic root of the main components i.

Table 7 Agricultural Science and Technology site principal component scores and order

\begin{tabular}{|c|c|c|c|c|c|c|c|}
\hline & $\mathrm{Y1}$ & $\mathrm{Y} 2$ & Y3 & $\mathrm{Y} 4$ & Y5 & score & order \\
\hline China Agricultural & & & & & & & \\
\hline $\begin{array}{l}\text { Science and Technology } \\
\text { Information Network }\end{array}$ & 1.958 & 0.16 & -0.088 & -0.093 & 0.539 & 0.729 & 4 \\
\hline $\begin{array}{l}\text { Hunan Agricultural Scienc } \\
\text { and Technology } \\
\text { Information Port }\end{array}$ & 1.441 & -0.02 & 0.08 & 0.154 & 0.353 & 0.556 & 9 \\
\hline
\end{tabular}


Guizhou Agricultural

Science and Technology

Information Network

1.221

$\begin{array}{ll}-0.374 & 0.424\end{array}$

$0.154 \quad 0.312$

18

Chinese agricultural

extension network

1.659

0.50

$-0.2$

$-0.141$

0.694

$0.702 \quad 6$

Shandong Agricultural

Science and Technology

nformation Network

0.091

0.201

$-0.239$

$0.644 \quad 0.592$

8

Shanxi Agricultural Science

and Technology

Information Network

1.641

0.27

$-0.543$

0.149

0.509

11

National Agricultural

Science Data

Sharing Center

1.746

0.097

0.432

0.092

0.234

$0.721 \quad 5$

Golden Agriculture

Network

$0.415 \quad 0.811$

0.131

0.397

$1.045 \quad 1$

Hangzhou Agricultural

Science and Technology

Information Network

1.117

$-0.016-0.14$

0.108

0.096

0.373

17

Liaoning Luyuan

Agricultural Science and

Technology Information

0.786

0.575

$0.172 \quad 0.257$

0.449

0.517

10

Network

Chinese Academy of

Agricultural Sciences

Network

1.977

0.174

$-0.06$

0.493

$-0.087$

0.749

3

Anhui Academy of

Agricultural Sciences

Network

1.264

$-0.394 \quad 0.018$

0.204

0.772

0.459

14

Zhongshan, Guangdong

Agricultural Science and

Technology Park

0.403

0.753

0.306

0.126

0.181

0.401

16

Hainan Agricultural Science

1.148

0.496

$-0.096$

$-0.327$

0.167

0.455

15 
and Technology

110 network

Nong Bo Technology

$$
\begin{array}{lllllll}
1.866 & 0.931 & -0.579 & 0.486 & 0.789 & 0.901 & 2
\end{array}
$$

Beijing agricultural

information network

0.168

$-0.233$

$-0.245$

$0.472 \quad 0.608$

Tianjin Agricultural

Information Network

$\begin{array}{lllllll}1.166 & -0.2 & 0.265 & 0.039 & 0.889 & 0.504 & 12\end{array}$

Nine hundred

million Network

\section{5 analysis and suggestion}

We compare the ranking of this paper with the Alexa ranking, and the results are shown in Table 8:

Table 8 Comparison of the ranking of this paper with Alexa

\begin{tabular}{|c|c|c|c|}
\hline website name & article & rank & Alexa rank \\
\hline Golden Agriculture Network & 1 & 2 & \\
\hline Nong Bo Technology & 2 & 1 & \\
\hline Chinese Academy of Agricultural Sciences Network & 3 & 3 & \\
\hline $\begin{array}{l}\text { China Agricultural Science and Technology Information } \\
\text { Network }\end{array}$ & 4 & 4 & \\
\hline National Agricultural Science Data Sharing Center & 5 & 5 & \\
\hline Chinese agricultural extension network & 6 & 6 & \\
\hline Beijing agricultural information network & 7 & 7 & \\
\hline $\begin{array}{l}\text { Shandong Agricultural Science and Technology Information } \\
\text { Network }\end{array}$ & 8 & 9 & \\
\hline Hunan Agricultural Science and Technology Information Port & 9 & 8 & \\
\hline $\begin{array}{l}\text { Liaoning Luyuan Agricultural Science and Technology } \\
\text { Information Network }\end{array}$ & 10 & 11 & \\
\hline $\begin{array}{l}\text { Shanxi Agricultural Science and Technology Information } \\
\text { Network }\end{array}$ & 11 & 10 & \\
\hline Tianjin Agricultural Information Network & 12 & 14 & \\
\hline Nine hundred million Network & 13 & 15 & \\
\hline Anhui Academy of Agricultural Sciences Network & 14 & 13 & \\
\hline Hainan Agricultural Science and Technology 110 network & 15 & 12 & \\
\hline
\end{tabular}


Zhongshan, Guangdong Agricultural Science and Technology Park

Hangzhou Agricultural Science and Technology Information

Network

Guizhou Agricultural Science and Technology Information

Network

From table 8 we can get the following results:

(1) We can see,in this paper the first top seven sites is consistent with Alexa ranking, but the first and the second ranking is not consistent. This is because in Alexa ranking,its information flow rank is predominant factor, the impact of other parameters is very small. At the same time also can be seen,when the site information flow reach a certain degree, the greater the information flow, the better the site of the index to maintain, the higher the overall ranking.

(2) The websites ranked in 8-18, this article ranking and Alexa have a larger discrepancy, so we can see, Alexa for the websites comprehensive ranking is not high not has a very high reference value.

(3) Overall, the ranking of the national agricultural science and technology websites is higher than the local agricultural science and technology websites. But there are exceptions, such as nine hundred million network, so the nine hundred million network need to be further improved. Single from the national agricultural science and technology websites: Golden agriculture network, nong bo network and Chinese Academy of Agricultural Sciences network, the comprehensive ranking is higher, the utilization of its website is also higher. From the local agricultural science and technology websites: Beijing, Shandong, Hunan stay ahead, It explained that the Ranking of Agricultural Science and Technology websites are relevant with the local information level and agriculture level. Guangdong, Zhejiang although the level of economic development is higher, the level of agricultural information needs to be further improved.

In this paper, through construction agricultural science and technology websites evaluation model,Using principal component analysis to analysis, For 18 agricultural science and technology site ranking, And based on ranking results comparison with Alexa ranking, giving agricultural science and technology websites analysis and evaluation.Through this type of evaluation,can play an important promote role to agricultural science and technology websites healthy development and agricultural Information Development.

\section{Reference}

1. Sha Yong Zhong, Ou Yang Xia Evaluation of China Provincial websites influence_website link analysis and web impact factor measurement [J]. Beijing: Information and Documentation work, 2004

21. Li Chunping, Yang Yimin, Ge Yingyu compare of principal component analysis and analytic hierarchy process in quantitative evaluation of comprehensive index [J]. Nanjing: Journal of Nanjing University of Finances and Economics, 2005 
3. Du Jing, Li Daoliang; Li Hongwen; evaluation system of agricultural information websites in China: [J].Jiangxi: Jiangxi Agricultural Sciences, 2010

4 Liu Yicheng, Li Hua evaluation method and evaluation index system of agricultural website [J]. Beijing: agricultural network information, 2010 